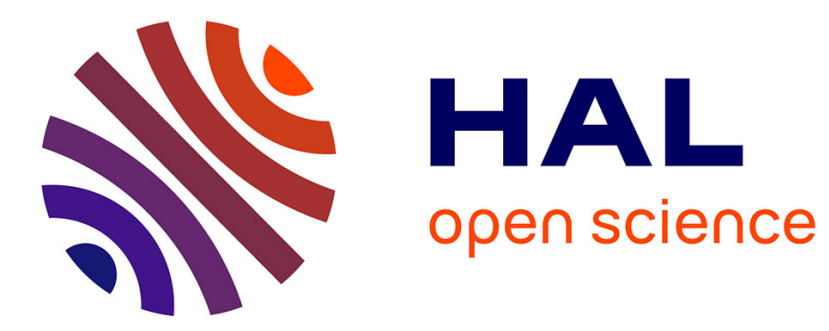

\title{
Delayed effects of a single dose of a neurotoxic pesticide (sulfoxaflor) on honeybee foraging activity
}

Lena Barascou, Fabrice Requier, Deborah Sené, Didier Crauser, Yves Le Conte, Cedric Alaux

\section{- To cite this version:}

Lena Barascou, Fabrice Requier, Deborah Sené, Didier Crauser, Yves Le Conte, et al.. Delayed effects of a single dose of a neurotoxic pesticide (sulfoxaflor) on honeybee foraging activity. Science of the Total Environment, In press, 805, 10.1016/j.scitotenv.2021.150351 . hal-03359304

\section{HAL Id: hal-03359304 https://hal.inrae.fr/hal-03359304}

Submitted on 30 Sep 2021

HAL is a multi-disciplinary open access archive for the deposit and dissemination of scientific research documents, whether they are published or not. The documents may come from teaching and research institutions in France or abroad, or from public or private research centers.
L'archive ouverte pluridisciplinaire HAL, est destinée au dépôt et à la diffusion de documents scientifiques de niveau recherche, publiés ou non, émanant des établissements d'enseignement et de recherche français ou étrangers, des laboratoires publics ou privés. 
Delayed effects of a single dose of a neurotoxic pesticide (sulfoxaflor) on honeybee foraging activity

5 Lena Barascou $^{1 *}$, Fabrice Requier $^{2}$, Deborah Sené ${ }^{1}$, Didier Crauser $^{1}$, Yves Le Conte $^{1}$, Cedric Alaux $^{1}$

${ }^{1}$ INRAE, Abeilles et Environnement, Avignon, France

${ }^{2}$ Université Paris-Saclay, CNRS, IRD, UMR Évolution, Génomes, Comportement et Écologie, F91198 Gif-sur-Yvette, France

10

*Corresponding authors: 1ena.barascou@inrae.fr 


\title{
Highlights
}

- Young honeybees were exposed to a sublethal dose of sulfoxaflor (16 or $60 \mathrm{ng}$ ).

- Both doses of sulfoxaflor reduced the daily flight activity and the total number of flights.

- Sulfoxaflor effects were delayed and emerged when bees transitioned to foraging activity.

- Time-to-effect measurements are needed to evaluate pesticide toxicity in honeybees.

\begin{abstract}
Pesticide risk-assessment guidelines for honeybees (Apis mellifera) generally require determining the acute toxicity of a chemical over the short-term through fix-duration tests. However, potential longlasting or delayed effects resulting from an acute exposure (e.g. a single dose) are often overlooked, although the modification of a developmental process may have life-long consequences. To investigate this question, we exposed young honeybee workers to a single sublethal field-realistic dose of a neurotoxic pesticide, sulfoxaflor, at one of two amounts (16 or $60 \mathrm{ng}$ ), at the moment when they initiated orientation flights (preceding foraging activity). We then tracked in the field their flight activity and lifespan with automated life-long monitoring devices. Both amounts of sulfoxaflor administered reduced the total number of flights but did not affect bee survival and flight duration. When looking at the time series of flight activity, effects were not immediate but delayed until foraging activity with a decrease in the daily number of foraging flights and consequently in their total number ( 24 and $33 \%$ less for the 16 and $60 \mathrm{ng}$ doses, respectively). The results of our study therefore blur the general assumption in honeybee toxicology that acute exposure results in immediate and rapid effects and call for long-term recording and/or time-to-effect measurements, even upon exposure to a single dose of pesticide.
\end{abstract}

Keywords: Ecotoxicology, bees, acute exposure, sublethal effects, pesticide risk assessment

\section{Introduction}

Within the framework of the pesticide risk assessment procedure, test guidelines require toxicological data on honeybees (Apis mellifera), a major pollinator of crops (Garibaldi et al. 2013) and wild plants (Hung et al. 2018). The first tier assessment relies on acute and chronic toxicity tests measuring the survival rate of bees over the duration of the tests, i.e. 48 hours and 10 days for acute and chronic exposure, respectively (OECD 1998a, b, 2013; OECD 2017). Thus, long-term mortality risks are often neglected in pesticide risk assessment, especially when effects on bee mortality occur not during but after chronic exposure to pesticides (i.e. after 10 days) (Dechaume Moncharmont et al. 2003; Rondeau et al. 2015). In addition, there is growing evidence for long-term sublethal effects upon chronic 
exposure to pesticides, such as the impairment of bee behavior, physiology or colony performance (Faucon et al. 2005; Sandrock et al. 2014; Prado et al. 2019; Colin et al. 2019; Al Naggar and Baer 2019; Hesselbach et al. 2020; Traynor et al. 2021). These data therefore show that time-to-effect experiments rather than fixed-duration tests are required for evaluating chronic toxicity (Rondeau et al. 2015; Simon-Delso et al. 2018; Bommuraj et al. 2021).

Similarly, long-lasting or delayed effects induced by an acute exposure have often been neglected. For instance, in the acute toxicity tests, mortality rate is measured over 48 hours and to a maximum of $96 \mathrm{~h}$ if the mortality increases by more than 10\% after the first 24 h (OECD 1998a, b). Moreover, sublethal effects have been generally assayed immediately or over the days following acute exposure to pesticides (Barascou et al. 2021). In fact, relatively little is known about the occurrence of long-lasting or delayed effects upon acute exposure (Schneider et al. 2012; Shi et al. 2020). After exposure to a single dose, a rapid reduction in pesticide concentration is generally observed in honeybees, which contributes to shortening the exposure to the toxic compound (Ardalani 2021; Barascou et al. 2021b). Relatively short-term effects can thus be expected; however, some pesticides may cause in-depth changes in bee physiology. For instance, neurotoxic insecticides, by targeting the neurotransmission pathways of insects, impact the neural plasticity, and brain function and structure of bees (Cabirol and Haase 2019). Thus, single pesticide exposure may lead to life-long impacts if they inhibit or modify a physiological and/or developmental process in the bee brain.

In honeybees, foraging activity is preceded by orientation flights, during which individuals develop highly complex cognitive capacities essential to navigation and homing (Capaldi and Dyer 1999; Degen et al. 2016). The experience accumulated during this pre-foraging stage then positively influences their foraging capacities and lifespan (Prado et al. 2020). We therefore hypothesized that a perturbation of this neurocognitive process by a neurotoxin could trigger chronic effects. To test this hypothesis we exposed bees at 7-days old, the median age of first orientation flights (Requier et al. 2020; Prado et al. 2020), to two sublethal doses of sulfoxaflor and tracked their flight activity and lifespan with automated life-long monitoring devices (optic bee counters) (Prado et al. 2019, 2020). We expected a modification of bee behavioral performance, given that sulfoxaflor is a new sulfoximine-based insecticide that shares a mode of action with neonicotinoids as selective agonists of nicotinic acetyl choline receptors (nAChRs) (Zhu et al. 2011; Sparks et al. 2013), and nAChRs play a central role in honeybee cognition (Gauthier and Grünewald 2012) .

\section{Materials and methods}

\section{Experimental setup}

Experiments were performed in a peri-urban area (Avignon, France, $43^{\circ} 540 \mathrm{~N}-4^{\circ}-520 \mathrm{E}$ ) with honeybees (Apis mellifera) from INRAE livestock. Newly emerged bees were collected from 3 colonies and marked with a data-matrix barcode ( $3 \mathrm{~mm}$ of diameter) glued on the thorax (Sader $\left.{ }^{\circledR}\right)$. 
They were then released into a colony equipped with a bee counter, which consists of a camera that monitors the hive entrance and image analysis software that detects and registers the activity of bees (direction: in or out of the hive, and time of activity: day, hour, minute, and second) (Prado et al. 2020). The experiment was repeated five times in 2019 ( 2 in May, 2 in June and 1 in July) using three different colonies equipped with bee counters ( 2 colonies were used twice). Each time, between 500 and 800 bees were introduced into colonies (see Table S1 for details). Colonies consisted of fiveframes with similar population size (around 10000 adult worker bees) and resource storage (honey and pollen). They were all treated against the parasite Varroa destructor the previous year (Apistan).

\section{Exposure to sulfoxaflor}

Tagged bees were allowed to develop normally for 7 days after their introduction into colonies. They were then collected and randomly assigned to experimental groups $(n=64-126$ bees per experimental group; Table S1). Bees were individually fed with $2 \mu \mathrm{L}$ of a solution of $30 \%(\mathrm{w} / \mathrm{v})$ sucrose, $0.1 \%$ acetone and sulfoxaflor at $5 \mu \mathrm{g} / \mathrm{ml}$ or $25 \mu \mathrm{g} / \mathrm{ml}$, which corresponded to a theoretic exposure of 10 and $50 \mathrm{ng}$ of sulfoxaflor/bee and to the $\sim \mathrm{LD}_{50} / 15$ and $\mathrm{LD}_{50} / 3$ reported by EFSA for in-hive (i.e. young) bees (146 ng/bee) (EFSA 2014). Control bees were individually fed with pesticide-free syrup (30\% $(\mathrm{w} / \mathrm{v})$ sucrose and $0.1 \%$ acetone).

The doses were chosen based on pesticide residue data found in pollen and nectar. Depending on the application rates and the crops, field residue studies reported levels of sulfoxaflor ranging from 0.04 to $2.37 \mathrm{mg} / \mathrm{kg}$ and from 0.15 to $2.78 \mathrm{mg} / \mathrm{kg}$ respectively in nectar and pollen collected by bees (U.S. EPA 2019). Considering that young bees consume between 35 and $60 \mathrm{mg}$ of nectar and 6 and $10 \mathrm{mg}$ of pollen per day (Rortais et al. 2005; Rodney and Purdy 2020), we could reasonably assume an exposure to sulfoxaflor between 1.4 and $142 \mathrm{ng}$ in nectar and between 0.9 and $27.8 \mathrm{ng}$ in pollen.

After exposure, bees were placed in plastic cages $(10.5 \mathrm{~cm} \times 7.5 \mathrm{~cm} \times 11.5 \mathrm{~cm})$ (Pain 1966) and kept for $60 \mathrm{~min}$ in the dark to allow them to ingest the sucrose solution before releasing them into their host colony. Individual flight behavior was recorded continuously from day 1 (introduction date) to day 45 . Stock solutions of sulfoxaflor (Techlab, France) were prepared with acetone, aliquoted and conserved at $-20^{\circ} \mathrm{C}$. The exact concentrations were checked with LC-MS/MS (European Standard EN 15662:2018 procedure) and resulted in $8 \mu \mathrm{g} / \mathrm{ml}$ and $30 \mu \mathrm{g} / \mathrm{ml}$ for the prepared sulfoxaflor concentrations, which corresponded to a real exposure of $16 \mathrm{ng} / \mathrm{bee}$ and $60 \mathrm{ng} / \mathrm{bee}$, respectively.

\section{Measuring bee life-history traits}

After exposure to the treatments, we tracked 1521 bees overall ( 3 experimental groups $\mathrm{x} 5$ replicates). Bees without at least one exit and entrance sequence (i.e. a flight sequence) were excluded from analyses, thus longevity and behavioral data were successfully recorded for 1108 bees. This loss was attributable to the loss of the tag number, the ejection of some tagged bees by nestmates, or an early death of individuals (just after re-introduction). Among the 1108 tracked bees, we obtained data for 
407 control bees, and 376 and 325 bees exposed to 16 and $60 \mathrm{ng}$ of sulfoxaflor, respectively (Table S1).

For the analysis of flight activity, exit-entrance sequences shorter than $2 \mathrm{sec}$ or longer than $180 \mathrm{~min}$ were excluded (Requier et al. 2020; Prado et al. 2020). The last detection for each barcoded bee was used to calculate bee survival over the 45 days of the experiment. The age at onset of foraging (AOF) was computed for each bee using the aof function developed in the aof R-package (Requier and Rebaudo 2020).

\section{Data analysis}

Data were analyzed using the statistical software R v4.0.3 (R Core Team 2020). Survival analyses were performed with the Kaplan-Meier method, using the survival package (Therneau 2021) and followed by a log-rank test for the comparison of survival between treatments. Data were transformed in a survival table and the remaining bees were considered alive at day 45 .

Variations in flight activity in response to treatments, flight experience (flight activity before pesticide exposure) and age (fixed factors) were analyzed using GLMM fitted by Penalized Quasi-Likelihood (glmmPQL function), using the MASS R-package (Venables and Ripley 2002). The total number of flights, the daily number of flights and the daily duration of flights over the 45 days were fitted with a Quasi-poisson error distribution due to over-dispersion in the data. The total duration of flight activity ( $\log _{10}$ transformed) and the AOF were fitted with a Gaussian error distribution, using the $\operatorname{glmmPQL}$ function. We introduced a quadratic term $\left(\mathrm{age}^{2}\right)$ into our daily flight activity models to account for a non-linear pattern of the observed relationship between daily flight activity and bee age. Multiple comparisons between levels of treatment were performed using the Tukey method in the glht function of the multcomp package (Hothorn et al. 2008). Variations in the total number and duration of flights were analyzed with treatment and flight experience as fixed factors, and replicate as a random factor. Variations in the daily activity (number and duration of flights) of each bee were analyzed with treatment and bee age as fixed factors, and replicate and bee identity as random factors. Effects of treatment on the AOF were investigated with replicate as a random factor. The replicate variable was considered as a random factor in the models given that this variable accounted for seasonal variability between bee cohort introductions performed between May and July.

\section{Results}

\section{Bee survival}

Bee survival did not significantly differ between experimental groups, demonstrating that the tested doses were non-lethal (Kaplan-Meier: $\mathrm{p}=0.1$; log Rank test, control vs. dose $16 \mathrm{ng}$ : $\mathrm{p}=0.56$; control vs. dose $60 \mathrm{ng}: \mathrm{p}=0.19$, and dose 16 ng vs. dose $60 \mathrm{ng}$ : $\mathrm{p}=0.12$; Fig. S1).

\section{Total flight activity}


At day 7 (day of exposure to sulfoxaflor), the percentage of bees that had already performed their first flight did not differ between experimental groups $(19.10 \pm 0.01 \%$ control bees, $18.74 \pm 0.02 \%$ and $14.81 \pm 0.001 \%$ bees exposed to 16 or $60 \mathrm{ng}$ of sulfoxaflor, respectively; $\chi^{2}=0.0012, \mathrm{df}=2$, $\mathrm{P}=0.999$ ). As expected, the total flight activity of bees before pesticide exposure did not differ between experimental groups (Table S2 and S3).

However, the total number of flights was significantly affected by the exposure to sulfoxaflor; bees exposed to $16 \mathrm{ng}$ and $60 \mathrm{ng}$ of sulfoxaflor made significantly fewer trips over the 45 days $(28.06 \pm$ 40.21 days and $21.25 \pm 24.88$ days, respectively) than control bees (33.23 \pm 64.22 days; Table 1; Fig. 1A). No difference in the number of flights was observed between the two pesticides doses (Table S4). The total number of flights after exposure to the pesticide treatment was not affected by flight experience (Table 1; Fig. 1A). The total duration of flight activity was not affected by exposure to sulfoxaflor (16 ng: $53166.8 \pm 63681.79 \mathrm{sec}, 60 \mathrm{ng}: 47441.21 \pm 58916.81 \mathrm{sec}$ and control: $54117 \pm$ $65037.63 \mathrm{sec}$ ), but it was negatively related to flight experience (Table 1; Fig 1B). The sulfoxaflor exposure of $16 \mathrm{ng}$ balanced out this negative relationship, although the size effect of this interaction was rather small (Table 1; Fig. 1B).

\section{Time series of flight activity}

175 Overall, the daily number of flights was significantly lower in bees exposed to the lower or higher dose of sulfoxaflor compared to control bees (Table 2; Fig. 2A), and differed between the sulfoxaflor doses, with bees exposed to the higher dose performing less daily flights than bees exposed to the lower dose (Table S5). The daily number of flights also changed according to the age of bees. This relationship was significantly affected by both doses of sulfoxaflor, although the effect was less pronounced for the lower dose (Table 2; Fig. 2A). Young bees belonging to the different treatment groups performed a similar number of daily flights, but their daily activity started to differentiate once they reached the AOF (age at onset of foraging). This latter did not differ between treatment groups $(14.71 \pm 5.27$ for control bees, $14.92 \pm 5.02$ and $14.11 \pm 4.47$ for bees exposed to 16 or $60 \mathrm{ng}$ of sulfoxaflor, respectively; GLMM, dose $16 \mathrm{ng}: \mathrm{p}=0.703$ and dose $60 \mathrm{ng}$ : $\mathrm{p}=0.261$; Table S6). Consequently, the number of foraging flights (i.e. flights performed after the AOF) was lower in sulfoxaflor-exposed bees as compared to control bees $(32.60 \pm 51.19)$ but did not differ between the two doses $(24.75 \pm 27.93$ and $21.62 \pm 22.29$, respectively for bees exposed to 16 or $60 \mathrm{ng}$ of sulfoxaflor; GLMM, dose $16 \mathrm{ng}: \mathrm{p}<0.01$ and dose $60 \mathrm{ng}$ : $\mathrm{p}<0.005$; Table S7).

The daily duration of flights was not affected by treatments (Table 2; Fig 2B). Only bee age had an effect. Similarly, to the daily number of flights, the duration increased with age up to the age of 30days old and then declined (Table 2; Fig 2B).

\section{Discussion}


In the present study, we showed that acute exposure in honeybees does not necessarily cause shortterm effects but can generate delayed effects, as previously found in others insects (Beketov and Liess 2008; Wolz et al. 2021). Long-term effects following exposure to a single dose of pesticide have been previously described in honeybees. However, contrary to our study, latency effects were not investigated and effects were only reported at doses that significantly increased honeybee mortality (Schneider et al. 2012; Shi et al. 2020). The sulfoxaflor doses we tested (16 and $60 \mathrm{ng} / \mathrm{bee}$ ) were below the LD50 determined for in-hive bees (146 ng/bee) (EFSA 2014) and proved to be non-lethal since no mortality increase was found as compared to control groups over the 45 days of monitoring. Recently, a lower LD50 has been reported for forager bees (55 ng/bee) (Azpiazu et al. 2021). The lack of toxicity of a similar dose in our experiment seems to confirm that in-hive bees are less sensitive to insecticides than forager bees (Tosi and Nieh 2019), although this might not be a general rule as it could depend on the pesticide type (Rinkevich et al. 2015). Another possible explanation for the nontoxicity of the doses in our study is that we monitored bee survival in field conditions. Control honeybees live less long in field conditions than in the laboratory, and therefore the risk of death of experimental groups relative to control groups tend to be reduced in field conditions as compared to the laboratory (Alaux et al. 2014).

210 Although both doses of sulfoxaflor significantly reduced the number of flights performed by bees, the total duration of flight activity was not affected, as would be expected from a lower number of flights but of similar duration. This might be explained by the natural variation in the duration of flights combined with the fact that the effect of sulfoxaflor on daily activity only emerged at about the time bees transitioned to foraging activity, i.e. a week after exposure to the pesticide. Interestingly, bees that had longer flight activity before exposure had shorter activity afterwards, suggesting that bees have a defined time-budget for their flight activity. We are cautious in our interpretation, because bees were experimentally manipulated during their activity; this work remains to be investigated with nonmanipulated free-flying bees. This relationship between flight experience and the duration of flight activity after treatment was affected by the lower sulfoxaflor dose, which resulted in bees flying for a rather fixed amount of time regardless their flight experience. The underlying mechanisms are not known but the effect was quite marginal and driven by a few bees.

An increase in oxidative stress and cell apoptosis, as well as a modification of immunocompetence, have been described upon sublethal exposure to sulfoxaflor (Chakrabarti et al. 2020; Al Naggar and Paxton 2021; Li et al. 2021). However, the behavioral impairments we observed are more in line with an impact on bee cognition. Since sulfoxaflor and neonicotinoids have a similar mode of action (agonist of nAChRs), and neonicotinoids are known to negatively influence bee behavior through impact on cognition (Belzunces et al. 2012; Siviter et al. 2018), we can reasonably assume that sulfoxaflor also affected bee behavioral performance through cognitive impairments. In our experiments, bees were exposed to sulfoxaflor when they initiated their orientation flights. It is therefore possible that sulfoxaflor affected their learning abilities, explaining why bees made later and 
fewer foraging flights. By testing the olfactory conditioning performances of honeybee foragers, Siviter et al. (2019) did not find any negative effects of acute sulfoxaflor exposure on learning and memory. However, besides the lower doses ( 0.05 to $2.5 \mathrm{ng}$ ), the tests were performed immediately after exposure to sulfoxaflor. The response to sulfoxaflor we found took more than a few days to develop and could therefore be considered delayed. The latency of response to pesticide may depend on many factors, such as the rates of absorption and distribution and the speed of action at the target site. But it may also depend on the physiological process that is affected. Interestingly, by analyzing the effect of imidacloprid (neonicotinoid) on habituation of the proboscis extension reflex, Guez et al. (2001) found a contrasting effect between 7- and 8-day-old bees. This effect seemed to be associated with a differential expression of two subtypes of nAChRs during bee behavioral maturation i.e. transition from nurse to forager tasks, (Guez et al. 2003). Later, it was found that during their behavioral maturation, young bees exhibit massive changes in brain gene expression, which are essentially completed at 8 days old (Whitfield et al. 2006) and coincide with structural brain changes (Farris et al. 2001). Altogether these studies provide strong evidence for developmental change in the neurophysiological state of 1-week old bees which might explain the effects of sulfoxaflor. By affecting this neurodevelopmental process essential to behavioral maturation, a single dose of neurotoxin might cause intrinsic changes in the bee brain and therefore impair future foraging performances.

Whilst much work remains to investigate the occurrence of long-term effects after acute exposure, our findings blur the general assumption in honeybee toxicology that acute exposure results in immediate and short-term effects. Therefore, long-term recording and/or time-to-effect measurements are needed, even upon exposure to a single dose of pesticide, to avoid a potential underestimation of pesticide toxicity.

\section{Competing interests}

The authors declare that they have no competing interests.

\section{Acknowledgments}

This project received funding from the European Horizon 2020 research and innovation program under grant agreement no. 773921 (LB, YLC and CA).

\section{Author Contributions}

L.B., Y.L.C and C.A. conceived the study. L.B., D.S., D.C. and C.A. conducted the experiments. L.B., C.A. and F.R. analysed the data, Y.L.C. and C.A. contributed to reagents. L.B, C.A and F.R. wrote the manuscript. All authors read and reviewed the manuscript.

\section{References}


Al Naggar Y, Baer B (2019) Consequences of a short time exposure to a sublethal dose of Flupyradifurone (Sivanto) pesticide early in life on survival and immunity in the honeybee (Apis mellifera). Sci Rep 9:19753. https://doi.org/10.1038/s41598-019-56224-1

Al Naggar Y, Paxton RJ (2021) The novel insecticides flupyradifurone and sulfoxaflor do not act synergistically with viral pathogens in reducing honey bee (Apis mellifera) survival but sulfoxaflor modulates host immunocompetence. Microb Biotechnol 14:227-240. https://doi.org/10.1111/1751-7915.13673

275 Alaux C, Crauser D, Pioz M, et al (2014) Parasitic and immune modulation of flight activity in honey bees tracked with optical counters. J Exp Biol 217:3416-3424. https://doi.org/10.1242/jeb.105783

Ardalani H (2021) Dietary quercetin impacts the concentration of pesticides in honey bees. Chemosphere 262:127848. https://doi.org/10.1016/j.chemosphere.2020.127848

Azpiazu C, Bosch J, Bortolotti L, et al (2021) Toxicity of the insecticide sulfoxaflor alone and in combination with the fungicide fluxapyroxad in three bee species. Sci Rep 11:6821. https://doi.org/10.1038/s41598-021-86036-1

Barascou L, Brunet J-L, Belzunces L, et al (2021a) Pesticide risk assessment in honeybees: Toward the use of behavioral and reproductive performances as assessment endpoints. Chemosphere 276:130134. https://doi.org/10.1016/j.chemosphere.2021.130134

Barascou L, Sene D, Barraud A, et al (2021b) Pollen nutrition fosters honeybee tolerance to pesticides. R Soc open sci 8:210818. https://doi.org/10.1098/rsos.210818

Beketov MA, Liess M (2008) Acute and delayed effects of the neonicotinoid insecticide thiacloprid on seven freshwater arthropods. Environ Toxicol Chem 27:461. https://doi.org/10.1897/07322R.1

Belzunces LP, Tchamitchian S, Brunet J-L (2012) Neural effects of insecticides in the honey bee. Apidologie 43:348-370. https://doi.org/10.1007/s13592-012-0134-0

Bommuraj V, Chen Y, Birenboim M, et al (2021) Concentration- and time-dependent toxicity of commonly encountered pesticides and pesticide mixtures to honeybees (Apis mellifera L.). Chemosphere 266:128974. https://doi.org/10.1016/j.chemosphere.2020.128974

Cabirol A, Haase A (2019) The Neurophysiological Bases of the Impact of Neonicotinoid Pesticides on the Behaviour of Honeybees. Insects 10:344. https://doi.org/10.3390/insects10100344

Capaldi EA, Dyer FC (1999) The role of orientation flights on homing performance in honeybees. J Exp Biol 202:1655-1666. https://doi.org/10.1242/jeb.202.12.1655

300 Chakrabarti P, Carlson EA, Lucas HM, et al (2020) Field rates of Sivanto ${ }^{\mathrm{TM}}$ (flupyradifurone) and Transform ${ }^{\circledR}$ (sulfoxaflor) increase oxidative stress and induce apoptosis in honey bees (Apis mellifera L.). PLoS ONE 15:e0233033. https://doi.org/10.1371/journal.pone.0233033

Colin T, Meikle WG, Wu X, Barron AB (2019) Traces of a neonicotinoid induce precocious foraging and reduce foraging performance in honey bees. Environ Sci Technol 53:8252-8261. https://doi.org/10.1021/acs.est.9b02452

Dechaume Moncharmont F-X, Decourtye A, Hennequet-Hantier C, et al (2003) Statistical analysis of honeybee survival after chronic exposure to insecticides. Environ Toxicol Chem 22:3088. https://doi.org/10.1897/02-578 
Degen J, Kirbach A, Reiter L, et al (2016) Honeybees Learn Landscape Features during Exploratory Orientation Flights. Curr Biol 26:2800-2804. https://doi.org/10.1016/j.cub.2016.08.013

EFSA (2014) Conclusion on the peer review of the pesticide risk assessment of the active substance sulfoxaflor. EFSA Journal 12:170

Farris SM, Robinson GE, Fahrbach SE (2001) Experience- and Age-Related Outgrowth of Intrinsic Neurons in the Mushroom Bodies of the Adult Worker Honeybee. J Neurosci 21:6395-6404. https://doi.org/10.1523/JNEUROSCI.21-16-06395.2001

Faucon J-P, Aurières C, Drajnudel P, et al (2005) Experimental study on the toxicity of imidacloprid given in syrup to honey bee (Apis mellifera) colonies: Toxicity of imidacloprid given in syrup to honey bee colonies. Pest Manag Sci 61:111-125. https://doi.org/10.1002/ps.957

Garibaldi LA, Steffan-Dewenter I, Winfree R, et al (2013) Wild Pollinators Enhance Fruit Set of Crops Regardless of Honey Bee Abundance. Science 339:1608-1611. https://doi.org/10.1126/science. 1230200

Gauthier M, Grünewald B (2012) Neurotransmitter Systems in the Honey Bee Brain: Functions in Learning and Memory. In: Galizia CG, Eisenhardt D, Giurfa M (eds) Honeybee Neurobiology and Behavior. Springer Netherlands, Dordrecht, pp 155-169

Guez D, Belzunces LP, Maleszka R (2003) Effects of imidacloprid metabolites on habituation in honeybees suggest the existence of two subtypes of nicotinic receptors differentially expressed during adult development. Pharmacol Biochem Behav 75:217-222. https://doi.org/10.1016/S0091-3057(03)00070-4

Guez D, Suchail S, Gauthier M, et al (2001) Contrasting effects of imidacloprid on habituation in 7and 8-day-old honeybees (Apis mellifera). Neurobiol Learn Mem 76:183-191. https://doi.org/10.1006/nlme.2000.3995

Hesselbach H, Seeger J, Schilcher F, et al (2020) Chronic exposure to the pesticide flupyradifurone can lead to premature onset of foraging in honeybees Apis mellifera. J Appl Ecol 57(3):609618. https://doi.org/10.1111/1365-2664.13555

Hothorn T, Bretz F, Westfall P (2008) Simultaneous inference in general parametric models. Biom J 50:346-363. https://doi.org/10.1002/bimj.200810425

Hung K-LJ, Kingston JM, Albrecht M, et al (2018) The worldwide importance of honey bees as pollinators in natural habitats. Proc R Soc B 285:20172140. https://doi.org/10.1098/rspb.2017.2140

340 Li J, Zhao L, Qi S, et al (2021) Sublethal effects of Isoclast ${ }^{\mathrm{TM}}$ Active (50\% sulfoxaflor water dispersible granules) on larval and adult worker honey bees (Apis mellifera L.). Ecotoxicology and Environmental Safety 220:112379. https://doi.org/10.1016/j.ecoenv.2021.112379

OECD (1998a) Test No. 213: Honeybees, acute oral toxicity test, OECD. Paris

OECD (1998b) Test No. 214: honeybees, acute contact toxicity test, OECD. Paris

OECD (2013) Test No. 237: honey bee (Apis mellifera) larval toxicity test, single exposure, OECD. Paris

OECD (2017) Test No. 245: honey bee (Apis mellifera L.), chronic oral toxicity test (10-day feeding), OECD. Paris 
Pain J (1966) Note technique nouveau modèle de cagettes expérimentales pour le maintien d'abeilles en captivité. Ann Abeille 9:71-76. https://doi.org/10.1051/apido:19660106

Prado A, Pioz M, Vidau C, et al (2019) Exposure to pollen-bound pesticide mixtures induces longerlived but less efficient honey bees. Sci Total Environ 650:1250-1260. https://doi.org/10.1016/j.scitotenv.2018.09.102

Prado A, Requier F, Crauser D, et al (2020) Honeybee lifespan: the critical role of pre-foraging stage. R Soc open sci 7:200998. https://doi.org/10.1098/rsos.200998

R Core Team (2020) R: A language and environment for statistical computing. Vienna, Austria:R Foundation for statistical Computing

Requier F, Henry M, Decourtye A, et al (2020) Measuring ontogenetic shifts in central-place foraging insects: a case study with honey bees. J Anim Ecol 89:1860-1871. https://doi.org/10.1111/1365-2656.13248

Requier F, Rebaudo F (2020) aof: Ontogenetic Shifts in Central-Place Foraging Insects. R package version 0.1.2. https://cran.r-project.org/web/packages/aof/index.html

Rinkevich FD, Margotta JW, Pittman JM, et al (2015) Genetics, synergists, and age affect insecticide sensitivity of the honey bee, Apis mellifera. PLoS ONE 10:e139841. https://doi.org/10.1371/journal.pone.0139841

Rodney S, Purdy J (2020) Dietary requirements of individual nectar foragers, and colony-level pollen and nectar consumption: a review to support pesticide exposure assessment for honey bees. Apidologie. https://doi.org/10.1007/s13592-019-00694-9

Rondeau G, Sánchez-Bayo F, Tennekes HA, et al (2015) Delayed and time-cumulative toxicity of imidacloprid in bees, ants and termites. Sci Rep 4:5566. https://doi.org/10.1038/srep05566

Rortais A, Arnold G, Halm M-P, Touffet-Briens F (2005) Modes of honeybees exposure to systemic insecticides: estimated amounts of contaminated pollen and nectar consumed by different categories of bees. Apidologie 36:71-83. https://doi.org/10.1051/apido:2004071

Sandrock C, Tanadini M, Tanadini LG, et al (2014) Impact of Chronic Neonicotinoid Exposure on Honeybee Colony Performance and Queen Supersedure. PLoS ONE 9:e103592. https://doi.org/10.1371/journal.pone.0103592

Schneider S, Eisenhardt D, Rademacher E (2012) Sublethal effects of oxalic acid on Apis mellifera (Hymenoptera: Apidae): changes in behaviour and longevity. Apidologie 43:218-225. https://doi.org/10.1007/s13592-011-0102-0

Shi J, Yang H, Yu L, et al (2020) Sublethal acetamiprid doses negatively affect the lifespans and foraging behaviors of honey bee (Apis mellifera L.) workers. Sci Total Environ 738:139924. https://doi.org/10.1016/j.scitotenv.2020.139924

Simon-Delso N, San Martin G, Bruneau E, Hautier L (2018) Time-to-death approach to reveal chronic and cumulative toxicity of a fungicide for honeybees not revealed with the standard ten-day test. Sci Rep 8:7241. https://doi.org/10.1038/s41598-018-24746-9

Siviter H, Koricheva J, Brown MJF, Leadbeater E (2018) Quantifying the impact of pesticides on learning and memory in bees. J Appl Ecol 55:2812-2821. https://doi.org/10.1111/13652664.13193 
Siviter H, Scott A, Pasquier G, et al (2019) No evidence for negative impacts of acute sulfoxaflor exposure on bee olfactory conditioning or working memory. PeerJ 7:e7208. https://doi.org/10.7717/peerj. 7208

Sparks TC, Watson GB, Loso MR, et al (2013) Sulfoxaflor and the sulfoximine insecticides: Chemistry, mode of action and basis for efficacy on resistant insects. Pestic Biochem Physiol 107:1-7. https://doi.org/10.1016/j.pestbp.2013.05.014

395 Suchail S, Guez D, Belzunces L (2001) Discrepancy between acute and chronic toxicity induced by imidacloprid and its metabolites in Apis mellifera. Environ Toxicol Chem 20:2482-2486. https://doi.org/10.1002/etc.5620201113

Therneau T (2021) A Package for Survival Analysis in R. R package version 3.2-11. https:/CRAN.Rproject.org/package $=$ survival.

Tosi S, Nieh JC (2019) Lethal and sublethal synergistic effects of a new systemic pesticide, flupyradifurone $\left(\right.$ Sivanto $\left.^{\circledR}\right)$, on honeybees. Proc R Soc B 286:20190433. https://doi.org/10.1098/rspb.2019.0433

Traynor KS, vanEngelsdorp D, Lamas ZS (2021) Social disruption: Sublethal pesticides in pollen lead to Apis mellifera queen events and brood loss. Ecotoxicol Environ Saf 214:112105. https://doi.org/10.1016/j.ecoenv.2021.112105

U.S. EPA (2019) Sulfoxaflor: Ecological Risk Assessment for Section 3 Registration for Various Proposed New Uses. Washington, D.C.

Venables WN, Ripley BD (2002) Modern Applied Statistics with S, Fourth edition. Springer, New York

410 Whitfield CW, Ben-Shahar Y, Brillet C, et al (2006) Genomic dissection of behavioral maturation in the honey bee. Proc Natl Acad Sci 103:16068-16075. https://doi.org/10.1073/pnas.0606909103

Wolz M, Schrader A, Müller C (2021) Direct and delayed effects of exposure to a sublethal concentration of the insecticide $\lambda$-cyhalothrin on food consumption and reproduction of a leaf beetle. Sci Total Environ 760:143381. https://doi.org/10.1016/j.scitotenv.2020.143381

Zhu Y, Loso MR, Watson GeraldB, et al (2011) Discovery and Characterization of Sulfoxaflor, a Novel Insecticide Targeting Sap-Feeding Pests. J Agric Food Chem 59:2950-2957. https://doi.org/10.1021/jf102765x 
Figure 1. Total flight activity in response to pesticide treatments and flight experience. (A) Total number of flights and (B) total duration of flight activity (sec.) over 45 days ( $n=407$ control bees, $n=$ 376 and 325 bees exposed to 16 or $60 \mathrm{ng}$ of sulfoxaflor, respectively). Thick lines represent the model predictions with shaded areas indicating $1 / 2$ standard error. Colored marks show the distribution of raw data along the horizontal axis.

Figure 2. Time series of flight activity in response to pesticide treatments. (A) Number and (B) duration of daily flights (sec.) over bee lifetime ( $n=407$ control bees, $n=376$ and 325 bees exposed to 16 or $60 \mathrm{ng}$ of sulfoxaflor, respectively). Thick lines represent the model predictions with shaded areas indicating $1 / 2$ standard error and the dashed line represents the day of exposure to pesticides. The transition to foraging activity started on average at 14.5 days. Colored marks show the distribution of raw data along the horizontal axis. 
Table 1. Results of the generalized mixed effect models assessing the effects of pesticide treatments and flight experience on the total flight activity. Intercept represents the control bees. Flight experience corresponds to the flight activity of bees before exposure to pesticide.

\begin{tabular}{lrrr}
\hline Parameters & Estimate & Standard error & $\boldsymbol{p}$-value \\
\hline Total number of flights & & & \\
Intercept & 3.5824 & 0.1938 & $<\mathbf{0 . 0 0 1}$ \\
Flight experience (number of flights before pesticide exposure) & -0.1401 & 0.0736 & 0.0572 \\
Dose $16 \mathrm{ng}$ & -0.3391 & 0.1262 & $<\mathbf{0 . 0 1}$ \\
Dose $60 \mathrm{ng}$ & -0.5145 & 0.1509 & $<\mathbf{0 . 0 0 1}$ \\
Flight experience $\times$ Dose $16 \mathrm{ng}$ & 0.1510 & 0.0840 & 0.0725 \\
Flight experience $\times$ Dose $60 \mathrm{ng}$ & 0.1345 & 0.1178 & 0.2537 \\
\hline Total duration of flight activity (sec.) & & & \\
Intercept & 4.2666 & 0.1120 & $<\mathbf{0 . 0 0 1}$ \\
Flight experience (duration of flight activity before pesticide exposure) & -0.0001 & 0.00003 & $<\mathbf{0 . 0 1}$ \\
Dose 16 ng & 0.00334 & 0.06016 & 0.9568 \\
Dose 60 ng & -0.0138 & 0.06050 & 0.832 \\
Flight experience $\times$ Dose $16 \mathrm{ng}$ & 0.0001 & 0.00004 & $\mathbf{0 . 0 3 3 9}$ \\
Flight experience $\times$ Dose $60 \mathrm{ng}$ & 0.0001 & 0.00005 & 0.2898 \\
\hline
\end{tabular}


Table 2. Results of the generalized mixed effect models assessing the effects of pesticide treatments and age on the time series of flight activity. Intercept represents the control bees. Age ${ }^{2}$ represents a quadratic term to take into account a non-linear pattern of the observed relationship between daily flight activity and bee age.

\begin{tabular}{|c|c|c|c|}
\hline Parameters & Estimate & Standard error & $p$-value \\
\hline \multicolumn{4}{|c|}{ Time series of flight number } \\
\hline Intercept & -1.9041 & 0.1516 & $<0.001$ \\
\hline Age (days) & 0.3471 & 0.0168 & $<0.001$ \\
\hline Dose $16 \mathrm{ng}$ & 0.4730 & 0.2033 & 0.0202 \\
\hline Dose $60 \mathrm{ng}$ & 1.0872 & 0.2170 & $<0.001$ \\
\hline Age $\times$ Dose 16 ng & -0.0545 & 0.0230 & 0.018 \\
\hline Age $\times$ Dose $60 \mathrm{ng}$ & -0.1393 & 0.0248 & $<0.001$ \\
\hline $\mathrm{Age}^{2}$ & -0.0083 & 0.0004 & $<0.001$ \\
\hline $\mathrm{Age}^{2} \times$ Dose $16 \mathrm{ng}$ & 0.0012 & 0.0006 & 0.0555 \\
\hline $\mathrm{Age}^{2} \times$ Dose $60 \mathrm{ng}$ & 0.0036 & 0.0007 & $<0.001$ \\
\hline \multicolumn{4}{|c|}{ Time series of flight duration (sec.) } \\
\hline Intercept & 3.9608 & 0.1836 & $<0.001$ \\
\hline Age (days) & 0.2996 & 0.0141 & $<0.001$ \\
\hline Dose $16 \mathrm{ng}$ & -0.0811 & 0.2047 & 0.6920 \\
\hline Dose $60 \mathrm{ng}$ & 0.3517 & 0.2128 & 0.0987 \\
\hline Age $\times$ Dose 16 ng & 0.0140 & 0.0201 & 0.4861 \\
\hline Age $\times$ Dose 60 ng & -0.0235 & 0.0212 & 0.2691 \\
\hline $\mathrm{Age}^{2}$ & -0.0047 & 0.0003 & $<0.001$ \\
\hline $\mathrm{Age}^{2} \times$ Dose $16 \mathrm{ng}$ & -0.0005 & 0.0005 & 0.2859 \\
\hline $\mathrm{Age}^{2} \times$ Dose $60 \mathrm{ng}$ & 0.0004 & 0.0005 & 0.3779 \\
\hline
\end{tabular}


Figure 1

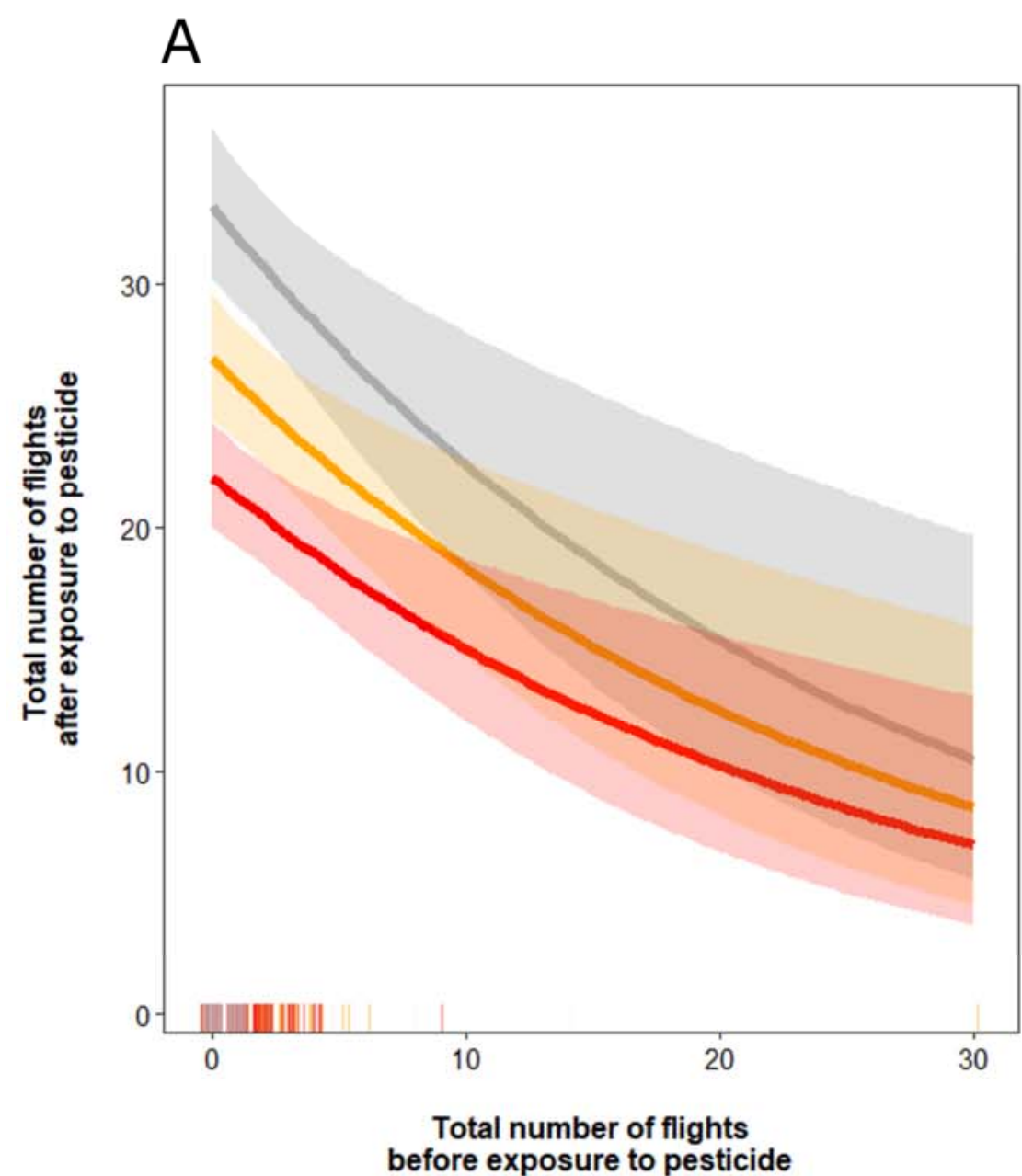

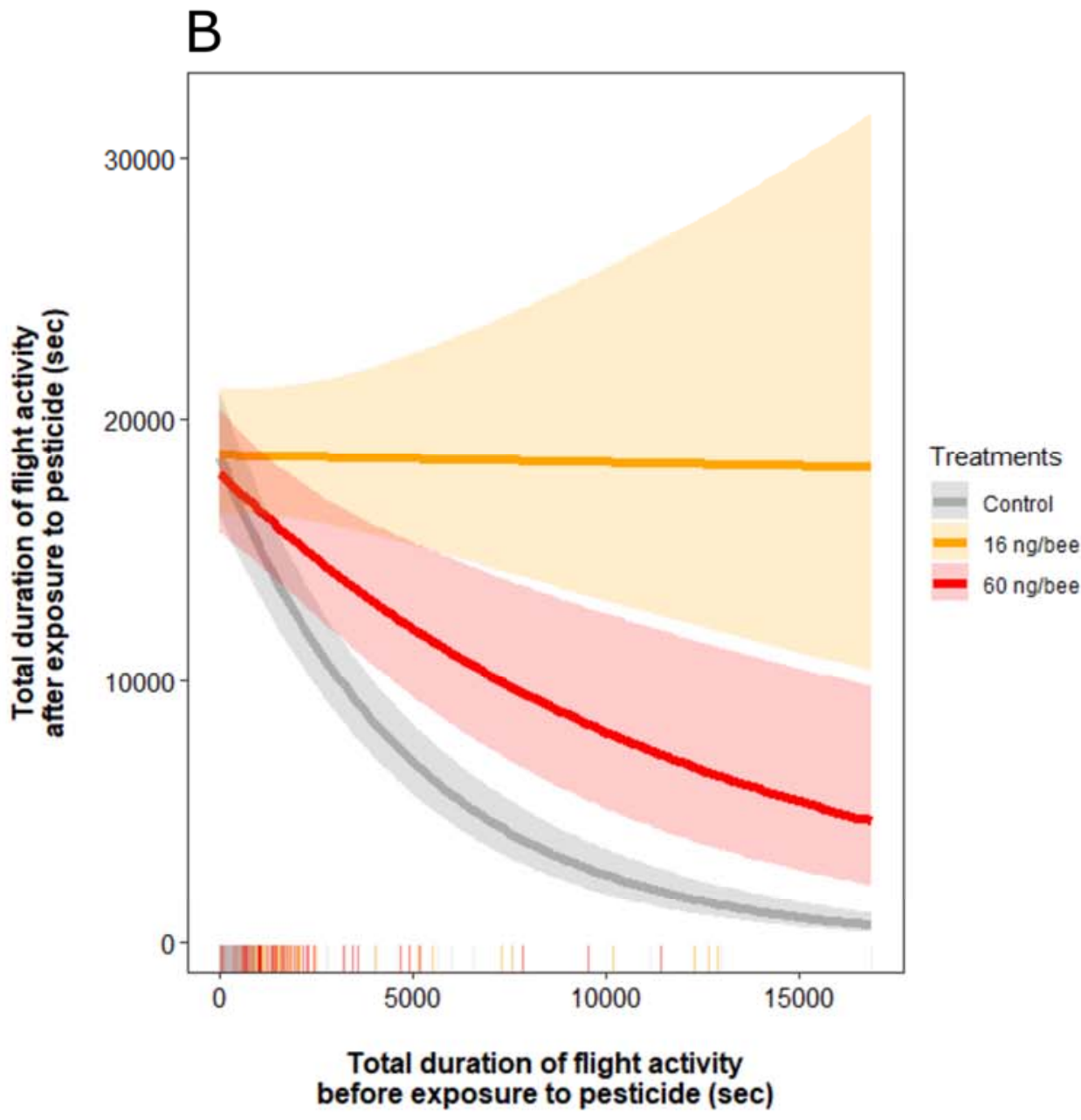


Figure 2

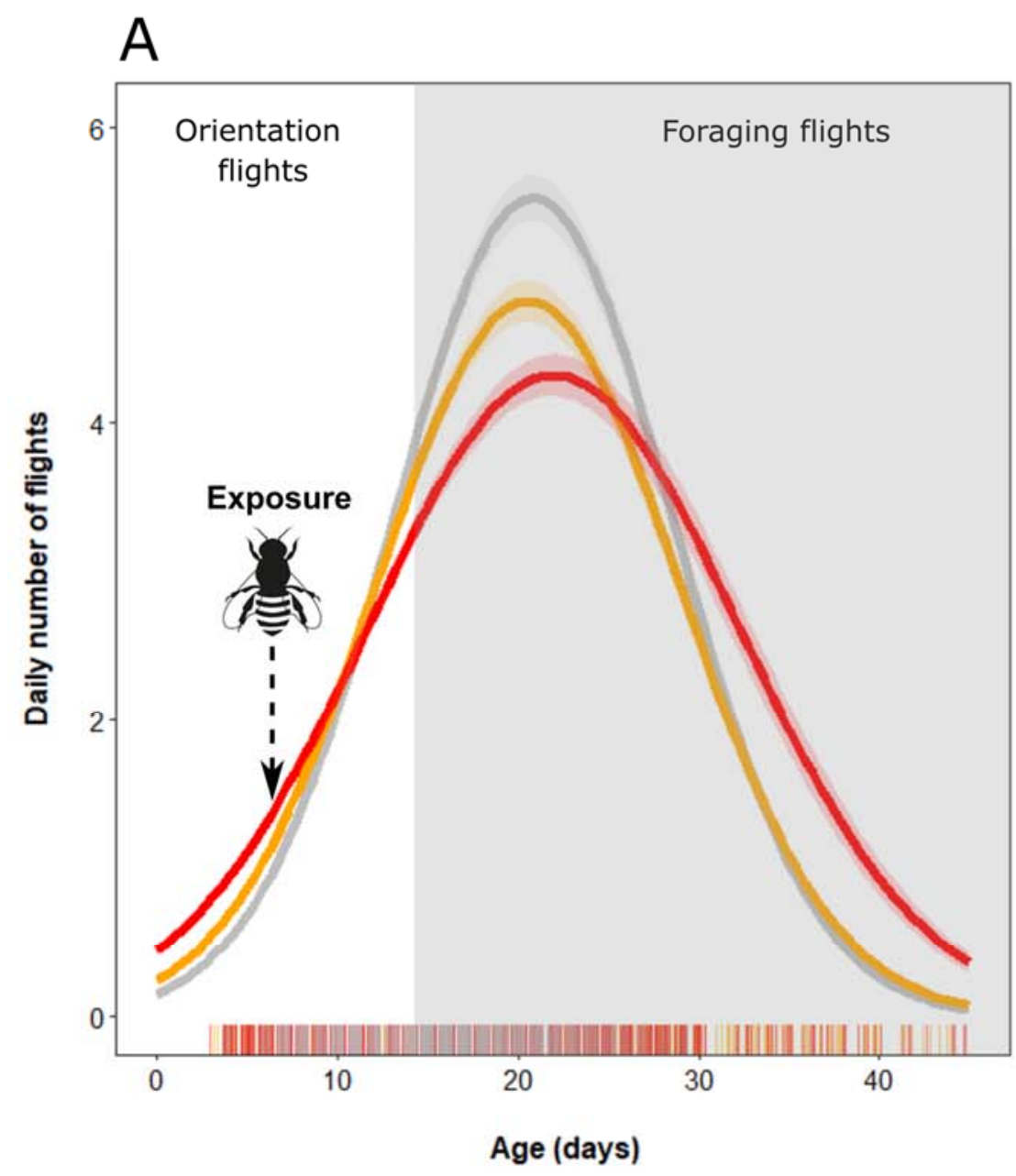

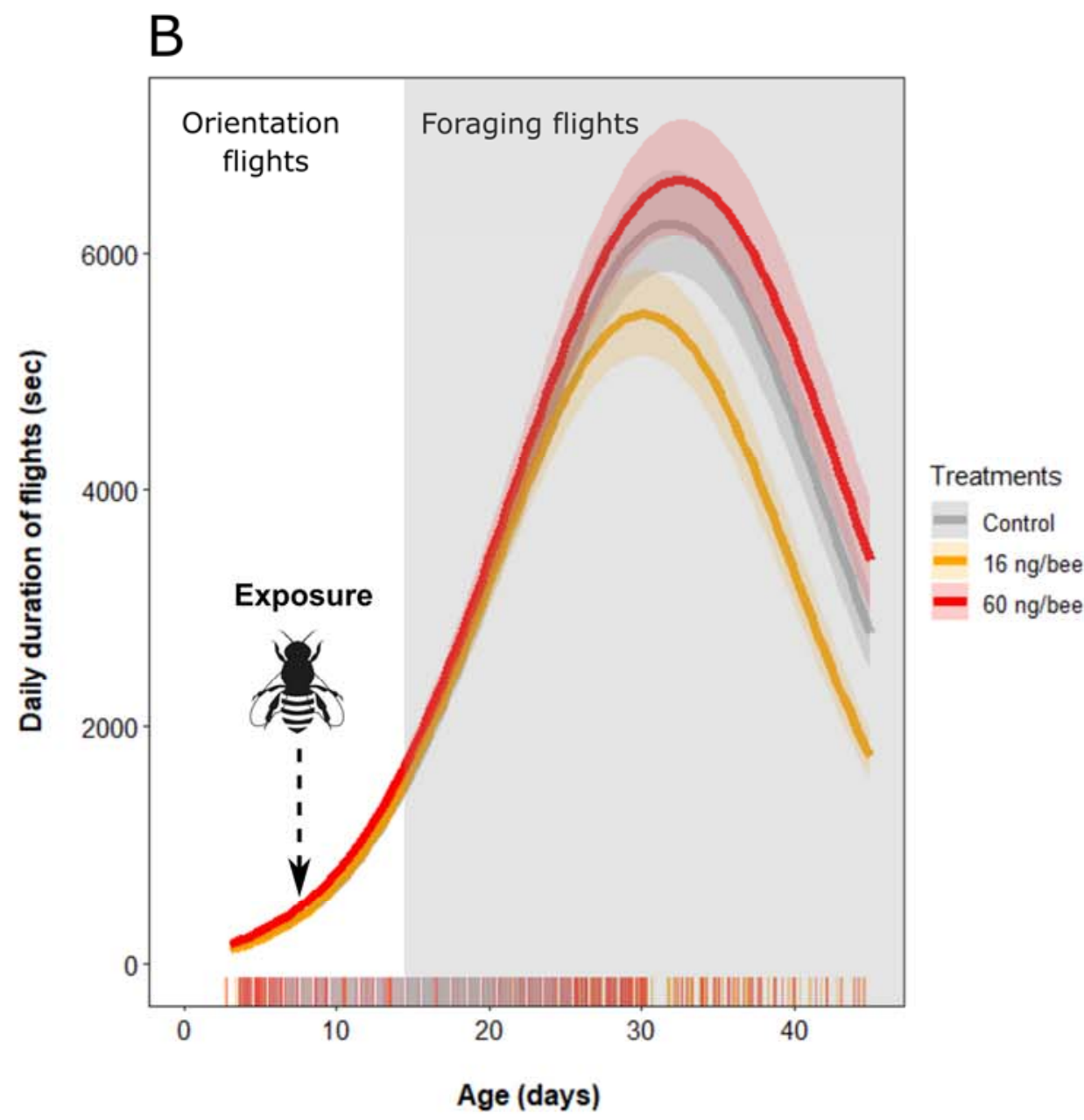

